Original Article

\title{
DO WOMEN REALLY LIKE TAKEN MEN? RESULTS FROM A LARGE QUESTIONNAIRE STUDY
}

\author{
Antonios Vakirtzis \\ Institute of Integrative Biology, University of Liverpool \\ S. Craig Roberts \\ Department of Psychology, University of Stirling
}

\begin{abstract}
Nonindependent mate choice occurs when a female (focal female) is influenced in her mate choice by the choices of other females (model females), though sometimes male choice can be similarly influenced. In humans the study of this phenomenon has been almost exclusively experimental, with the perceived level of attractiveness of opposite-sex faces being influenced by manipulation of the attractiveness of their putative partner. As useful as these experimental studies are, the question of how validly they capture real-life social processes has not been addressed. Here we present the results of a questionnaire study which analyzed responses from 206 male and 175 female participants, both singles and people in a relationship. As predicted, paired men reported more opposite-sex interest than paired women, whereas the opposite was true for single respondents. Furthermore, the amount of opposite-sex interest reported by paired men correlated with the attractiveness of their partner, whereas this correlation between partner attractiveness and opposite-sex interest did not hold for female respondents. We suggest that this contrast is related to sex differences in benefits of nonindependent mate choice arising from sexspecific reproductive constraints. Our results are consistent with the kinds of effects recorded in laboratory studies, and provide evidence that non-independent mate choice plays at least some role in actual relationship dynamics.
\end{abstract}

Keywords: Nonindependent mate choice, mate choice copying, mate quality bias, questionnaire, sex differences, humans

\section{Introduction}

Nonindependent mate choice usually occurs when a choosing female (focal female) is influenced in her mate choice by the choices of other females (model females) (Dugatkin, 1992; Pruett-Jones, 1992; Westneat et al., 2000), though sometimes (and in a smaller number of species) males can also be influenced by the choices of other males (Schlupp \& Ryan, 1997;

AUTHOR NOTE: Please direct correspondence to Antonios Vakirtzis, Institute of Integrative Biology, Crown Street, University of Liverpool, L69 7ZB, Liverpool, UK. Email: a.vakirtzis@liv.ac.uk 
Widemo, 2006). Mate choice copying (reviewed in Dugatkin, 1996; Galef, 2008; Vakirtzis, 2011; White, 2004) is a widely studied type of nonindependent mate choice in which females are more likely to choose a male if he has previously mated with other model females and less likely to choose him if he has been rejected (Dugatkin, 1992; Witte \& Ueding, 2003). To date, the study of mate choice copying has been confined primarily to promiscuous and polygynous species, which are more suitable for the evolution of copying (Galef, 2008; Vakirtzis, 2011; Vakirtzis \& Roberts, 2009a; 2010).

It has recently been suggested that for a largely monogamous species like humans, mate choice copying is unlikely to be an adequate conceptual device for a number of reasons (Vakirtzis \& Roberts 2009a, 2010). To begin with, modern Western human societies exhibit relatively low male mating skew, with studies showing that most men have one stable partner at a time (Adimora et al, 2007; Greeley et al, 1990; Seidman \& Rieder, 1994). This means that whether a man has a partner or not will not be as informative a cue as it is in other species with marked male mating skews and large proportions of unmated males. Another problem is that humans have substantial paternal care, meaning that a copying woman is likely to have to share paternal care with the offspring of other women. Vakirtzis \& Roberts (2009a; 2010) have suggested the operation of a related process termed mate quality bias. Ideally mate quality bias involves a perfectly monogamous system (every male has one partner) with frequent turnover of mates, in which females adjust their evaluation of the male in accordance with the attractiveness of his partner. Males that are paired with attractive females increase their mate value, whereas the opposite is true for males paired with unattractive females (see Vakirtzis \& Roberts, 2009a; 2010). Though largely monogamous, humans still retain some promiscuous/polygynous characteristics, so these authors have suggested that elements of both processes (mate choice copying and mate quality bias) may be found in our species (Vakirtzis \& Roberts, 2010).

With the exception of one early questionnaire study (Platek et al., 2001), the study of nonindependent mate choice to date has been exclusively experimental. Some earlier studies were more or less direct applications of mate choice copying, namely presenting female raters with male stimuli that were supposedly single or in a relationship and comparing the two groups. Men in a relationship are sometimes found to have an advantage compared to men who are single (Eva \& Wood, 2006; Parker \& Burkley, 2010) though often studies fail to find this effect (Uller \& Johansson, 2003; Milonoff et al, 2007; Waynforth, 2007). Later studies, however, have often presented all males with a partner, and modified solely the attractiveness of this partner. These studies generally find that women prefer men that are paired to attractive women and give lower attractiveness ratings to the same men when they are presented as paired with unattractive women (Little et al, 2008; Vakirtzis \& Roberts, 2009b; Waynforth, 2007; Yorzinski \& Platt, 2010; see also Sigall \& Landy, 1973).

There have, however, been few studies that examine whether these experimental results have their counterparts in real-life romantic relationships. This is troubling given that sometimes these experiments have produced conflicting results. For example, the question of whether men exercise nonindependent mate choice (i.e. whether they are influenced by the male partners of women) has yet to be answered conclusively, with some studies finding positive results (Little et al., 2008; Place et al., 2010; Yorzinski \& Platt, 2010) whereas others produce null results (Dunn \& Doria, 2010; Parker \& Burkley, 2010; Vakirtzis \& Roberts, 2009b). As has been suggested elsewhere (Vakirtzis \& Roberts, 2010), evolutionary considerations suggest it is unlikely that men "copy" other men's mate choice or that they are even attracted to women who are paired with attractive men. This is because whereas women can supplement their assessment of a male (relating to his resource holding potential, social status, personality traits and other unobservable characteristics) by being sensitive to the attractiveness of his mate, men cannot supplement their 
assessment of a female by being sensitive to the attractiveness of her mate. Female mate value is largely dependent on physical attractiveness (an easily discernible cue), and the more desirable females don't necessarily form relationships with the most physically attractive men (see Vakirtzis \& Roberts, 2010).

The preceding discussion suggests that non-experimental approaches are needed for two reasons. Firstly, to provide external validity to the experimental method and weigh in favor of some experimental results. Secondly, to guide the experimentalist into formulating more focused and promising designs. Here we report a questionnaire study which constitutes, to the best of our knowledge, the largest and most detailed non-experimental undertaking in this field. We recruited both male and female subjects $(n=401)$ and asked them to indicate their agreement with certain statements that were intended to gauge romantic interest from opposite-sex individuals. We recruited both participants who were in a relationship and single participants, and analyzed each group separately by a) comparing male to female responses and b) correlating participants' responses with reported partner attractiveness, self-attractiveness, length of the relationship (or length of time being single) and patterns of social activities. We predicted that paired men would report more opposite-sex interest than paired women (in comparison to when they were single), and single men less opposite-sex interest than single women (in comparison to when they were in a relationship). We also predicted, for paired participants, that partner attractiveness would correlate positively with opposite-sex interest reported by male participants, but this would not be the case (or be less pronounced) for female participants.

\section{Methods}

\section{Recruitment of Subjects}

Four hundred and one subjects were recruited by convenience, mostly in libraries of the University of Liverpool and Liverpool John Moores University, or through social networking websites. An effort was made to recruit British subjects so as to reduce variance in the results due to cultural differences. Having been informed about the general aims (participants were told they would be participating in a study of how people are influenced in their choice of mate by the choices of other people), they were provided with a link to the online questionnaire and asked to complete it in their own time.

\section{Participants}

A total of 401 subjects participated in the study. Of these, 13 reported being homosexual (although the information sheet at the beginning of the questionnaire informed subjects the study was aimed at heterosexual people) and were excluded from the analysis. An additional 7 participants didn't answer past the questions on the first page of the questionnaire (relating to age, sex etc.) and were also excluded. A small number of the remaining 381 questionnaires were not completed in their entirety, which, in addition to the fact that some questions were not "forced," i.e., the participant was not required to fill them out in order for the questionnaire to continue, accounts for the fact that sample sizes vary slightly in different analyses. Three hundred and fifty eight of respondents were students, the non-students probably originating mostly from participants who were recruited via social networking websites. All but 54 of the participants were British. Of these 54 non-British subjects, 20 were Irish and only 10 were nonEuropean (Mexican, Brazilian, etc.), meaning that culturally this was a relatively homogeneous sample. Two hundred and six subjects were male (mean age \pm SD $21.6 \pm 2.2$ yrs) and 175 
Nonindependent mate choice in humans

female $(21.2 \pm 2.2 \mathrm{yrs})$. Men reported a median number of lifetime sexual partners of 5 (mean 9.7, range 0-89), whereas the corresponding median for women was 4 (mean 6.3, range 0-50). The slightly higher number of lifetime sexual partners reported by men is a well-known phenomenon (Smith, 1992; Wiederman, 1997). Interestingly, although the self-reported attractiveness of both males and females was approximately normally distributed, men on average gave themselves higher attractiveness ratings (mean \pm SE: $6.6 \pm 0.1$ vs. $6.1 \pm 0.1$ for females, $t=3.5, p=.0005$ ).

The first part of the analysis (see below) focused on the responses of 200 people who reported being in a romantic relationship. Of these, 104 were men (21.8 \pm 2.5 yrs, range 18-32) and 96 were women (20.0 2.2 yrs, range 18-32). Of these 200 people, $70 \%$ (73 men and 67 women) described their relationship as "dating only," $22 \%$ (22 men and 22 women) as "dating and living together" and the remaining $8 \%$ as "engaged," "engaged and living together" or "married." Although in the following we report the results for all categories of relationships combined, we ran separate analyses for the "dating only" category and the results were similar to those obtained for the overall sample. The remaining relationship categories were too small to allow for separate analyses.

The second part of the analysis examined responses given by singles. In total, 178 subjects reported being single, and of these 102 were men (21.5 \pm 1.9 yrs, range 18-29) and 76 $(21.3 \pm 2.2$ yrs, range 18-28) were women. Forty seven percent of men and $39 \%$ of women reported being single for over 12 months. Some subjects that reported never having been in a relationship were redirected to a later section of the questionnaire (see below) and thus excluded from this part of the analysis, since the items of interest in this section asked subjects to compare their experience of being single with their experience of being in their previous relationship, and those subjects that had never been in a relationship could not, by definition, make such a comparison. Twenty-two subjects reported never having been in a relationship, thereby reducing the sample size for this section of the questionnaire to $n=156$ ( 88 men and 68 women).

\section{Overview of Questionnaire}

The questionnaire consisted of an information sheet, a brief introductory fact-gathering section and three major sections. The introductory section asked for basic information such as sex, age, ethnicity, lifetime number of sexual partners, sexual orientation, self-rated attractiveness (on a 10-point scale, 10 being most attractive) and relationship status, i.e. single or in relationship (and the type of relationship). The answers given to the fields in this introductory section determined which parts of the questionnaire the subjects would subsequently view. The three main sections of the questionnaire were as follows.

The first section was viewed by those subjects (male and female) who were in a relationship. This section asked subjects various factual pieces of information regarding their relationship, such as the duration of the relationship, the length of time for which they had been single prior to entering their current relationship, and how frequently the couple visited the following social places: clubs/bars, eateries, cafes, cinemas and house parties. Frequency of visits was ordinally recorded on a 7-point ordinal scale which ranged from "almost never" to "almost daily." The relationship between a couple's frequency of social outings and nonindependent mate choice is a logical necessity; a couple that stay at home all the time and never venture together in public afford third individuals no possibilities to observe them together and adjust their evaluations accordingly. With regard to nonindependent mate choice, however, we should expect to find differences between the opportunities afforded, for instance, in a bar or club compared to, say, a restaurant (Hendrie et al, 2009). A related item was the question "To

Journal of Social, Evolutionary, and Cultural Psychology - ISSN 1933-5377 - Volume 6(1). 2012. 
what degree do you and your partner share the same social network (friends, acquaintances, colleagues etc)?" Participants could select one of four options: "entirely/almost entirely separate," "mostly separate," "mostly shared," "entirely/almost entirely shared." This "social circle overlap" item was intended to gauge another aspect of couples' social life, namely the extent to which the two partners' shared social circle could afford opportunities for nonindependent mate choice to take place. Subjects were also asked to rate their partners for attractiveness on a 10 point-scale, 10 being most attractive. Finally, and, most importantly, this section contained a number of statements about how respondents felt they were viewed by members of the opposite sex in the context of their relationship. These statements, always presented in random order, were the following (words in brackets refer to the statements viewed by female participants):

S1: In general, I feel that I have become more attractive to other women (men) since I started dating my girlfriend (boyfriend).

S2: When I go to a bar or club with my girlfriend (boyfriend) other women (men) seem to take notice of me.

S3: Women (Men) seem to look at me more when I'm with my girlfriend (boyfriend) than when I'm alone.

S4: Some women (men) who previously showed little or no interest in me seem to flirt with me since I started dating my girlfriend (boyfriend).

S5: The last time me and my girlfriend (boyfriend) went out together to a bar or club, I noticed that other women (men) were paying attention to me.

S6: In general, women (men) flirt more with me since I started dating my girlfriend (boyfriend).

Subjects indicated their agreement or disagreement with each of these statements on a 7-point scale from "strongly disagree" (1) to "strongly agree" (7).

The second major section of the questionnaire was targeted to male and female subjects who were single. This part of the questionnaire asked respondents to indicate how long they had been single for and how attractive their last partner had been, on the same 10-point scale as above. As with the first section, this section also contained a number of statements (presented in random order) with which participants were asked to agree or disagree. These statements related to how subjects felt they were viewed by the opposite sex outside the context of a relationship:

S7: In general, I feel that I have become less attractive to women (men) since I became single.

S8: Women (Men) seem to pay less attention to me since I broke up with my ex-girlfriend (exboyfriend).

S9: When I used to go to a bar or club with my ex-girlfriend (ex-boyfriend) other women (men) took notice of me; now they don't.

S10: Women (Men) flirt more with me since I broke up with my ex-girlfriend (boyfriend).

The third and final section of the questionnaire was viewed by all subjects, both male and female, regardless of whether they were single or in a relationship. This section presented a number of more general statements that related to various aspects of nonindependent mate choice and were always presented in random order:

S11: When I'm in a relationship, women (men) seem more interested in me.

S12: When I'm single, women (men) seem to show less interest in me.

S13: I would be turned off if I found out that my partner's ex-boyfriend (ex-girlfriend) was very ugly.

Journal of Social, Evolutionary, and Cultural Psychology - ISSN 1933-5377 - Volume 6(1). 2012. 
S14: I would lose some of my interest in a prospective dating partner if I found out she (he) had an unattractive ex.

S15: I would be less inclined to introduce my partner to other women (men) if she (he) was unattractive.

S16: I would be more inclined to 'show off' my partner to other women (men) if she (he) was attractive.

As can be seen, the first two statements (S11 and S12) related to participants' perceptions of their attractiveness when single as compared to being in a relationship (i.e., in their capacity as a "target male/female"). These two statements essentially asked the same thing, and were only phrased differently to establish the importance of phrasing. The next two (S13, S14) pertained to participants' own perceptions of how they would assess a current or potential mate in their capacity as "focal" males or females. The final two statements (S15, S16) pertained to the "flaunting" of an attractive partner. As with the first two statements, these two statements asked very similar things, although it is worth noting that in contrast to the first two statements which are logically equivalent, these are not equivalent.

Finally, all subjects filled out the Rosenberg self-esteem scale (Rosenberg, 1965) and the Social Information Processing subscale of the Tromso Social Intelligence Scale (Silvera et al, 2001).

In order to test for the predicted gender differences in nonindependent mate choice male and female responses to the same items were juxtaposed throughout all sections of the questionnaire. In particular we expected that men would express higher levels of agreement with statements that indicated the opposite sex was influenced by their (i.e., the respondents') partner. The self-esteem and social intelligence scores were used as covariates in Analysis of Covariance (ANCOVA) to ensure any gender differences were not spurious. Within each sex, variables like the attractiveness of participants' partners (current or past), self-rated attractiveness, the social activities of the couple (for partnered participants), participants' age and sexual experience were correlated with the dependent variables. Given that many of these former variables (like socialcircle overlap, frequency of outings to various social places) were defined on an ordinal scale, we used non-parametric correlations throughout. All tests were two-tailed.

\section{Results}

\section{People in Relationship}

Table 1 shows the results of the sex comparisons for the six statements that served as dependent variables in this section. The table reveals two very different classes of statements. Statements S1 (In general, I feel that I have become more attractive to other women since I started dating my girlfriend), S3 (Women seem to look at me more when I'm with my girlfriend (boyfriend) than when I'm alone), S4 (Some women who previously showed little or no interest in me seem to flirt with me since I started dating my girlfriend) and S6 (In general, women flirt more with me since I started dating my girlfriend) all showed highly significant sex differences with substantial effect sizes. As predicted, men agreed more than women with all of these statements. On the other hand, statements S2 (When I go to a bar or club with my girlfriend other women seem to take notice of me) and S5 (The last time me and my girlfriend went out together to a bar or club, I noticed that other women were paying attention to me) unexpectedly showed no sex differences at all. Why this difference?

Journal of Social, Evolutionary, and Cultural Psychology - ISSN 1933-5377 - Volume 6(1). 2012. 
Table 1. Comparison of Responses by Men and Women (Words in Brackets) who were in a Romantic Relationship

\begin{tabular}{|c|c|c|c|c|c|}
\hline Statement & $\begin{array}{c}\text { Male } \\
(n=103) \\
\text { mean } \pm \text { SE }\end{array}$ & $\begin{array}{c}\text { Female } \\
(n=94) \\
\text { mean } \pm \text { SE }\end{array}$ & $t(195)$ & $p$ & Cohen's $d$ \\
\hline $\begin{array}{l}\text { S1. In general, I feel that I have become more attractive to other } \\
\text { women (men) since I started dating my girlfriend (boyfriend). }\end{array}$ & $4.38 \pm 0.15$ & $3.68 \pm 0.15$ & 3.28 & .001 & 0.46 \\
\hline $\begin{array}{l}\text { S2. When I go to a bar or club with my girlfriend (boyfriend) } \\
\text { other women (men) seem to take notice of me. }\end{array}$ & $4.26 \pm 0.14$ & $4.28 \pm 0.14$ & -.076 & .940 & 0.01 \\
\hline $\begin{array}{l}\text { S3. Women (men) seem to look at me more when I'm with my } \\
\text { girlfriend (boyfriend) than when I'm alone. }\end{array}$ & $4.09 \pm 0.15$ & $3.24 \pm 0.15$ & 3.95 & $<.0001$ & 0.56 \\
\hline $\begin{array}{l}\text { S4. Some women (men) who previously showed little or no } \\
\text { interest in me seem to flirt with me since I started dating my } \\
\text { girlfriend (boyfriend). }\end{array}$ & $4.16 \pm 0.16$ & $3.45 \pm 0.16$ & 3.11 & .002 & 0.44 \\
\hline $\begin{array}{l}\text { S5. The last time me and my girlfriend (boyfriend) went out } \\
\text { together to a bar or club, I noticed that other women (men) were } \\
\text { paying attention to me. }\end{array}$ & $4.17 \pm 0.15$ & $4.29 \pm 0.15$ & -.587 & .558 & 0.08 \\
\hline $\begin{array}{l}\text { S6. In general, women (men) flirt more with me since I started } \\
\text { dating my girlfriend (boyfriend). }\end{array}$ & $4.01 \pm 0.15$ & $3.44 \pm 0.15$ & 2.70 & .008 & 0.38 \\
\hline
\end{tabular}

Note: Higher means indicate more agreement with the statement. Persons who were married saw identical statements with 'wife' instead of 'girlfriend' for men and 'husband' instead of 'boyfriend' for women.

A closer examination of the way the statements are structured suggests a very likely explanation. Statements S1, S3, S4 and S6 all explicitly ask participants to make a comparison between their experiences before and during their current relationship ( $\mathrm{S} 1, \mathrm{~S} 4$ and S6), or between when they are alone in public and when they are with their partner (S3). They are, in other words, statements of the difference between some measures of absolute and conditional probability of choice (see Pruett-Jones 1992, p.1001 for definitions). Assuming that nonindependent mate choice is more important in female mate choice, then this difference should be larger for the male population, and indeed this is what the results suggest. Statements 2 and 5, on the other hand, do not ask participants to make a comparison of this kind. They probably measure some aspects of conditional probability of choice, and at an aggregate population level there is no reason to expect any average difference between the female and male conditional probabilities of choice. In hindsight, therefore, it appears that statements 2 and 5 could have been better constructed or avoided altogether, although we think that their inclusion here can be very informative for future studies of this kind.

Given the somewhat subjective nature of some of these statements, it could be argued that the sex differences reported here are not genuine reflections of nonindependent mate choice but stem instead from differences in third variables like social intelligence or self-esteem. In particular, more socially intelligent people could be more attuned to subtle signals of interest from opposite-sex members, and people with higher self-esteem could be more inclined to perceive friendly interactions as flirtation. To rule out this possibility we repeated the previous comparisons but used participants' scores on the social intelligence and self-esteem scales as covariates in ANCOVA (since there were no systematic differences in either of these variables between men and women, their use as covariates is warranted). Table 2 shows the results. As can be seen, the inclusion of the two covariates did not alter the previously obtained sex differences, which remained highly significant for statements 1, 3, 4 and 6 but did not obtain for statements 2 and 5.

Journal of Social, Evolutionary, and Cultural Psychology - ISSN 1933-5377 - Volume 6(1). 2012. 
Table 2. Comparison of Responses by Men and Women in a Relationship with Social Intelligence and Self-Esteem as Covariates (See Previous Table for Description of Statements)

\begin{tabular}{ccccccccc}
\hline Statement & $\begin{array}{c}\text { Estimated male } \\
\text { mean }\end{array}$ & $\begin{array}{c}\text { Estimated female } \\
\text { mean }\end{array}$ & $F_{1,191}$ & $p$ & $\begin{array}{c}\text { Social intelligence } b \\
(p)\end{array}$ & $\begin{array}{c}\text { Self-esteem } \\
b(p)\end{array}$ & $\begin{array}{c}\text { Model } R^{2} \\
\text { adjusted }\end{array}$ \\
\hline S1 & 4.32 & 3.75 & 6.76 & .010 & $.368(.020)$ & $.053(.026)$ & .104 \\
S2 & 4.20 & 4.34 & 0.56 & .455 & $.316(.026)$ & $.053(.013)$ & .059 \\
S3 & 4.11 & 3.21 & 15.5 & .0001 & $.217(.183)$ & $-.014(.565)$ & .068 \\
S4 & 4.17 & 3.43 & 12.1 & .002 & $.397(.022)$ & $-.005(.839)$ & .059 \\
S5 & 4.06 & 4.41 & 2.76 & .098 & $.269(.076)$ & $.085(.001)$ & .091 & .047 \\
S6 & 4.01 & 3.43 & 6.76 & .010 & $.354(.028)$ & $.002(.920)$ & .047 \\
\hline
\end{tabular}

Note: Higher means indicate more agreement with the statement.

To simplify the remainder of the analysis and see if a clearer pattern could be discerned via an aggregation of items, we created a composite score (hereafter "composite interest") by averaging participants' responses to statements 1,3,4,6 (alphas: men .780, women .778). Due to the principle of aggregation (Rushton et al 1983), composite interest is almost certainly a more accurate measure of the dependent variable than any single statement in isolation. An ANCOVA (with the same factors and covariates as above) on composite interest revealed a highly significant gender difference (estimated means \pm SE: men $4.15 \pm .12$, women $3.46 \pm .12, F_{1,191}=15.7$, $p=.0001)$ with social intelligence $(b=.334, p=.009)$ but not self-esteem $(b=.009, p=.636)$ emerging as a significant covariate. This more informative aggregate score suggests that the relevant covariate is social intelligence rather than self-esteem.

We then examined the relationship between composite interest and participants' responses on variables like the reported attractiveness of their partner, their self-rated (i.e., the participants') attractiveness, the length of their relationship (in months), and the length of time for which they had been single prior to entering their current relationship. We included relationship length as a variable of interest in the questionnaire due to the simple fact that the longer a relationship lasts the more opportunities its members have to observe the reactions of the opposite-sex. Similarly, the length of time for which participants had been single prior to entering their current relationship should be related to the accuracy of one's estimate of his/her baseline attractiveness. For men, composite interest correlated only with partner attractiveness ( $r h o=.208, n=103, p=.035$ ) but not with self-rated attractiveness, relationship length, or length of being single prior to the current relationship (all $p>.28$ ). For women, composite interest did not correlate with partner attractiveness $(r h o=.050, n=92, p=.639)$, or with any of the other three variables (all $p>.26$ ).

We then examined the relationship between composite interest and the couples' patterns of social activities, i.e. how frequently they visited public places like bars or clubs, cafes, cinemas, restaurants/fast food eateries, and house parties. For male participants composite interest correlated significantly only with reported frequency of visits to house parties ( $r h o=.292, n=103, p=.003$ ), and, somewhat surprisingly, nonsignificantly with frequency of visits to bars/clubs (rho=.-.070, $n=103, p=.480)$. For female participants there was no relation between composite interest and frequency of visits to any of these social places (all $p>.19$; indeed, there were no correlations between females' responses on the 6 statements and frequency of visits to any of the five categories of social places: 30 correlations, all $p>.056$, whereas for males a number of correlations were significant). We then aggregated the frequency 
of visits to all five types of social places to produce a single composite score of 'overall frequency of social outings' but this did not correlate with composite interest for either men or women (both $p>.3$ ). It would thus seem that in relation to frequency of social outings every category of venue represents a qualitatively distinct class, and aggregation should be avoided.

Finally, we examined the relationship between composite interest and the "social circle overlap" item but the correlations were nonsignificant for both sexes.

\section{Singles}

Table 3 shows the four statements that subjects were asked to evaluate in this section, breaking down participants' responses by sex. Statement 10 (Women flirt more with me since I broke up with my ex-girlfriend) is reverse-keyed (a correlation matrix confirmed that the other three statements in this section were all highly positively correlated and were, in turn, all negatively correlated to S10, and that this pattern held for both men and women). As predicted, men on average gave higher scores for the first three statements, but women scored higher on statement 10, although this last difference was not significant. It is interesting to note that, qualitatively, the gender difference in S9 (When I used to go to a bar or club with my exgirlfriend other women took notice of me; now they don't) seems to fall into a category of its own as witnessed by the large effect size. In contrast to the other questions which are more general and refer to overall perceptions of self-attractiveness, this item is more circumscribed, directing the participant's attention to a very specific autobiographical domain.

Table 3. Comparison of Responses by Men and Women (Words in Brackets) who were Single

\begin{tabular}{|c|c|c|c|c|c|}
\hline Statement & $\begin{array}{l}\text { Male }(n=86) \\
\text { mean } \pm \text { SE }\end{array}$ & $\begin{array}{c}\text { Female } \\
(n=68) \\
\text { mean } \pm \text { SE }\end{array}$ & $t(152)$ & $p$ & Cohen's $d$ \\
\hline $\begin{array}{l}\text { S7. In general, I feel that I have become less attractive to } \\
\text { women (men) since I became single. }\end{array}$ & $3.33 \pm 0.19$ & $2.79 \pm 0.20$ & 2.0 & .052 & 0.32 \\
\hline $\begin{array}{l}\text { S8. Women (men) seem to pay less attention to me since I broke } \\
\text { up with my ex-girlfriend (ex-boyfriend). }\end{array}$ & $3.16 \pm 0.15$ & $2.71 \pm 0.16$ & 2.1 & .039 & 0.34 \\
\hline $\begin{array}{l}\text { S9. When I used to go to a bar or club with my ex-girlfriend (ex- } \\
\text { boyfriend) other women (men) took notice of me; now they } \\
\text { don't. }\end{array}$ & $3.86 \pm 0.14$ & $2.82 \pm 0.16$ & 4.8 & $<.001$ & 0.78 \\
\hline $\begin{array}{l}\text { S10. Women (men) flirt more with me since I broke up with my } \\
\text { ex-girlfriend (boyfriend). }\end{array}$ & $3.95 \pm 0.15$ & $4.29 \pm 0.18$ & -1.4 & .153 & 0.23 \\
\hline
\end{tabular}

Note: Higher means indicate more agreement with the statement. Persons who were married saw identical questions with 'wife' instead of 'girlfriend' for men and 'husband' instead of 'boyfriend' for women.

Do these sex differences stand out in sharper relief after individual differences in social intelligence and self-esteem have been controlled? To answer this we conducted a series of ANCOVAs with sex as the factor and social intelligence and self-esteem as covariates (as noted above the use of ANCOVA is warranted here). The results are shown in Table 4. The inclusion of the two covariates generally make the sex differences stand out in sharper relief, though social intelligence does not contribute to any of the four models. 
Table 4. Comparison of Responses by Single Men and Women with Social Intelligence and Self-Esteem as Covariates (See Previous Table for Description of Statements)

\begin{tabular}{lccccccc}
\hline Statement & $\begin{array}{c}\text { Estimated } \\
\text { male mean }\end{array}$ & $\begin{array}{c}\text { Estimated } \\
\text { female mean }\end{array}$ & $F_{1,148}$ & $p$ & $\begin{array}{c}\text { Social intelligence } \\
b(p)\end{array}$ & Self-esteem $b(p)$ & $\begin{array}{c}\text { Model } R^{2} \\
\text { adjusted }\end{array}$ \\
\hline S7. & 3.34 & 2.74 & 5.58 & .030 & $-.259(.141)$ & $-.071(.011)$ & .079 \\
S8. & 3.19 & 2.62 & 6.32 & .013 & $-.136(.338)$ & $-.054(.017)$ & .067 \\
S9. & 3.89 & 2.79 & 22.9 & $<.001$ & $-.145(.309)$ & $-.039(.082)$ & .144 \\
S10. & 3.90 & 4.37 & 3.68 & .057 & $-.029(.851)$ & $.051(.039)$ & .025 \\
\hline
\end{tabular}

Note: Higher means indicate more agreement with the statement

We reverse-scored statement S10 (Women flirt more with me since I broke up with my ex-girlfriend) and subsequently averaged all four statements into one composite score (hereafter "singles' composite") for every participant (alphas: male $=.722$, female=.822). An ANCOVA (with the same factors and covariates as above) on singles' composite confirmed the impression afforded by the examination of each statement separately: there was a highly significant effect of sex $\left(F_{1,148}=13.5, p<.001\right)$ with a significant contribution of self-esteem $(b=-.054, p=.004)$, while social intelligence was non-significant $(b=-.128, p=.277)$. These results are in contrast to those obtained for people in a relationship (reported above) where social intelligence rather than selfesteem was the significant covariate.

Finally, we examined the relation between singles' composite and a number of independent variables, namely self-rated attractiveness, attractiveness of previous partner and length of time since last relationship. For both men and women, attractiveness of previous partner and time since last relationship were unrelated to singles' composite; self-rated attractiveness, however, correlated negatively with singles' composite for both male ( $r h o=-.258$, $n=86, p=.016)$ and female participants ( $r h o=-.357, n=67, p=.003)$.

\section{General Questions}

This last section comprised a number of more general statements that were evaluated by all participants, regardless of relationship status (this group of respondents comprised the 200 subjects who were in a relationship, the 178 who were single, and 3 who had selected "not sure/rather not say' in the relationship status question). By "general," it is meant that the statements did not ask participants to reflect on their experiences during their current relationship or since their last relationship, but asked them to look at the more "global" picture of their sexual/romantic career. Table 5 breaks down the answers to the statements by sex. 
Table 5. Comparison of Responses by Men and Women (Words in Brackets)

\begin{tabular}{|c|c|c|c|c|c|}
\hline Question & $\begin{array}{c}\text { Male } \\
(n=199) \\
\text { mean } \pm \text { SE }\end{array}$ & $\begin{array}{c}\text { Female } \\
(n=170) \\
\text { mean } \pm \text { SE }\end{array}$ & $t(367)$ & $p$ & Cohen's $d$ \\
\hline $\begin{array}{l}\text { S11. When I'm in a relationship women (men) seem more } \\
\text { interested in me. }\end{array}$ & $4.28 \pm 0.09$ & $3.53 \pm 0.11$ & 5.2 & $<.001$ & 0.54 \\
\hline $\begin{array}{l}\text { S12. When I'm single women (men) seem to show less interest } \\
\text { in me. }\end{array}$ & $3.89 \pm 0.01$ & $3.25 \pm 0.11$ & 4.3 & $<.001$ & 0.45 \\
\hline $\begin{array}{l}\text { S13. I would be turned off if I found out that my partner's ex- } \\
\text { boyfriend (ex-girlfriend) was very ugly. }\end{array}$ & $2.97 \pm 0.11$ & $2.4 \pm 0.11$ & 3.6 & .001 & 0.38 \\
\hline $\begin{array}{l}\text { S14. I would lose some of my interest in a prospective dating } \\
\text { partner if I found out she (he) had an unattractive ex. }\end{array}$ & $2.71 \pm 0.11$ & $2.25 \pm 0.10$ & 3.1 & .002 & 0.32 \\
\hline $\begin{array}{l}\text { S15. I would be less inclined to introduce my partner to other } \\
\text { women (men) if she (he) was unattractive. }\end{array}$ & $3.96 \pm 0.12$ & $3.54 \pm 0.14$ & 2.2 & .025 & 0.23 \\
\hline $\begin{array}{l}\text { S16. I would be more inclined to 'show off' my partner to other } \\
\text { women (men) if she (he) was attractive. }\end{array}$ & $4.94 \pm 0.12$ & $4.34 \pm 0.15$ & 3.2 & .001 & 0.33 \\
\hline
\end{tabular}

Note: Higher means indicate more agreement with the statement.

As can be seen, there were significant sex differences across all statements, although in contrast to earlier sections these were not always in the expected direction (excluding the answers from the 22 subjects who had never been in a relationship did not alter these results). Men scored higher on every statement compared to women, whereas we had predicted this only for S11 (When I'm in a relationship women seem more interested in me), S12 (When I'm single women seem to show less interest in me), S15 (I would be less inclined to introduce my partner to other women if she was unattractive) and S16 (I would be more inclined to 'show off' my partner to other women if she was attractive). Statements S13 (I would be turned off if I found out that my partner's ex-boyfriend was very ugly) and S14 (I would lose some of my interest in a prospective dating partner if I found out she had an unattractive ex) asked participants to adopt the viewpoint of a focal male/female, and if nonindependent mate choice is indeed more influential in female compared to male choice then women should indicate more agreement with these statements.

The next part of the analysis focused on accounting for the variance in participants' responses to each of these statements separately on the basis of their age, lifetime number of sexual partners (used as a proxy for sociosexual orientation) and self-rated attractiveness. For men the only significant model was produced for S16 (I would be more inclined to 'show off' my partner to other women if she was attractive) which referred to partner 'flaunting' (overall model adjusted $R^{2}=.11, p<.001$; age (beta=-.240, $p=.002$ ), lifetime partners (beta=.308, $p<.001$ ), attractiveness (beta=.031, $p=.689)$ ). It is interesting to note that, the logically necessary positive correlation between age and lifetime number of sexual partners notwithstanding, the relation of these two variables with the dependent variable was of a different direction: age was (unexpectedly) negatively related to males' tendency to flaunt an attractive partner, whereas lifetime number of sexual partners was positively related. For women, all models were nonsignificant. 


\section{Discussion}

Prior to this study there had been only one non-experimental study of human nonindependent mate choice. Platek et al. (2001) asked an undergraduate sample whether they had ever experienced an increase in dating opportunities upon entering a new relationship. The large majority of both males and females indicated that they had this experience; moreover, the frequency of this effect correlated with the frequency of participants' heterosexual intercourse. Here we administered a more detailed questionnaire to a large sample of men and women. Summarizing the results briefly, the predicted sex difference of men reporting more interest from opposite-sex individuals when in a relationship vs. when single in comparison to what women report was confirmed both for participants who were in a relationship and those who were single at the time of the study. For example, men who were in a relationship expressed more agreement with statements like "In general, I feel that I have become more attractive to other women (men) since I started dating my girlfriend (boyfriend)" ( $p=.001)$, or "Some women (men) who previously showed little or no interest in me seem to flirt with me since I started dating my girlfriend (boyfriend)" ( $p=.002)$ than women who were in a relationship. The responses of single participants followed a similar pattern. Single men were more likely to agree with statements like "In general, I feel that I have become less attractive to women (men) since I became single" ( $p=.030)$ compared to single women. Aside from the differences arising from these direct comparisons between the two sexes, there were other differences which suggested nonindependent mate choice influences primarily female but not male choice. Most importantly, while the reported attractiveness of male participants' partners correlated positively with reported opposite-sex interest, there was no such correlation for female participants. The responses of male participants also correlated with aspects of the couple's social life, whereas those of female participants did not. These results disagree with some recent experimental results which not only suggest men employ nonindependent mate choice heuristics, but that that their influence is comparable to or even greater than it is for women (Little et al., 2008; Place et al., 2010; see also Platek et al., 2001). As discussed in the introduction, given the peculiarities of the human mating system there are strong theoretical reasons to expect that in our species only women resort to nonindependent mate choice, and the results of this study lend support to these theoretical predictions (see also Dunn \& Doria, 2010; Parker \& Burkley, 2010; Vakirtzis \& Roberts, 2010).

It is worth mentioning that although statistically significant, the sex differences reported here by participants in a relationship are between mild agreement by males and neutrality by females. Women always seem to get attention, regardless of context. Also, though here we included one reverse-coded item, future studies should perhaps include more, so as to ensure that participants are not being led to agree with the statements. Another point worth mentioning is that, although statistically significant, the correlation between the reported attractiveness of men's partners and sexual/romantic interest from other women was rather low at $r h o=.208$. This figure is not in line with the central role that the attractiveness of a man's partner is presumed to play in the process, and (unless the effect is genuinely very weak) could be seen as a lower bound estimate of the real relationship, produced here due to measurement error arising from participants' self reporting of partner attractiveness. A more satisfactory but at the same time more logistically demanding alternative would be the elimination of self-reports of attractiveness (both for partner and self) and their substitution with more objective measures. Ideally, researchers could obtain actual photographs of the couple and have these photographs rated for attractiveness by a panel of impartial third raters. In addition to providing a very accurate gauge of overall female attractiveness, such a procedure would also allow the more reliable recording

Journal of Social, Evolutionary, and Cultural Psychology - ISSN 1933-5377 - Volume 6(1). 2012. 
of the various subcomponents of attractiveness like body mass index (BMI; Tovée \& Cornelissen, 2001), waist-to-hip ratio (WHR; Singh, 1993; Singh and Young, 1995) or height and even non-attractiveness related cues like perceived personality traits (Penton-Voak et al, 2006).

The diversity of items on this questionnaire brings into sharp relief the contrast between the simplicity of experimental manipulations and the complexity of the real social world. Does the couple go out a lot together? Where do they go? Do they have many friends, or colleagues, or acquaintances in common? How long has the relationship lasted? For example, here we found that, consistent with predictions, there was a positive correlation between the frequency with which a couple went to house parties and the attention the man reported receiving from women in the context of his current relationship (see Hendrie et al., 2009). This positive correlation did not obtain for frequency of outings to less "sexy" places like cinemas or eateries. Other independent variables like the length of the relationship or the extent to which the two partners' social circle overlapped did not predict men's responses. But the list of variables that must be included does not end here, since personality differences between respondents must also be controlled. How adept or motivated is the man in picking out subtle indicators of interest from other women while with his partner? Does his elevated self-esteem (from having an attractive partner) get in the way of how he interprets these signals? Are paired men simply more approachable than single men in social settings? These are all questions that the social psychologist must take into account if he is to succeed in shedding light on real-life processes. Furthermore, as the number of variables increases, so does the sample size necessary to achieve satisfactory statistical power, which is another drawback of the non-experimental approach. Further tests to distinguish the underlying reasons for the effects we report are therefore needed before we can be sure that our reported results are robustly based on non-independent mate choice, although their consistency with experimental approaches leads us to think this is a likely mechanism.

In the end, no matter how well one controls for confounds, a statement like "In general, I feel that I have become more attractive to other women since I started dating my girlfriend" is bound to involve substantial error variance. It is for this reason that the items in the questionnaire must be aggregated to produce a single composite score for each participant. The principle of aggregation in psychological research states that the sum of a set of measurements provides a more stable and accurate estimate than any given measurement in isolation (Rushton et al., 1983). This is due to the fact that in aggregation the measurement errors associated with any particular measure tend to cancel each other out (Rushton et al., 1983). The results reported here support the notion that a composite score from the items administered to subjects in a romantic relation is a more meaningful measure than any single item on its own. Future studies with couples could use some of the items presented here as the basis for the creation of a validated scale. Also, future questionnaire studies of a slightly different format to the present one could perhaps employ more objective measures such as number of extra-pair copulations (EPCs) obtained over the course of various relationships, number of dates, telephone numbers secured and mate poaching attempts (Schmitt, 2004; Schmitt \& Buss, 2001; Parker \& Burkley, 2010).

We close by addressing a possible objection to our study design. We examined subjects' perceptions of nonindependent mate choice from their vantage point as target males/ females. In principle, this is only one of the two ways this area might be approached with a questionnairebased methodology. The other route would be to ask subjects questions from their vantage point as focal females or focal males, i.e., "How do you perceive persons of the opposite sex as a function of their relationship status? Does the attractiveness of their partner influence your attraction to them?" It could be argued that since the former approach examines subjects'

Journal of Social, Evolutionary, and Cultural Psychology - ISSN 1933-5377 - Volume 6(1). 2012. 
perceptions of how attractive they think other people find them, whereas the latter asks subjects to introspect into their own mate choice faculties, the former is less reliable than the latter. Our view is that the latter approach is particularly suited to experimental approaches used by ourselves and others (see Introduction), where participants simply indicate a preference for one of two presented alternatives. In contrast, it may not be so applicable in a questionnaire-based study because men and (especially) women may be reluctant to acknowledge that they find a taken man or a taken woman to be more attractive, given that this is socially unacceptable (see, for example, women's responses to statements S13 and S14 in Results section above). Furthermore, such a route would not have allowed for the collection of the relatively detailed information we were able to gather here: a third person would not be able to provide information as to the social life of the target person and his partner, the length of their relationship and other such information. Indeed, the only other similar study (Platek et al., 2001) used the same approach as we did, with broadly similar results, although they did not find the sex difference that we report.

\section{Received September 1, 2011; First revision received November 11, 2011; Second revision received December 1, 2011; Accepted December 1, 2011}

\section{References}

Adimora, A.A., Schoenbach, V.J., \& Doherty, I.A. (2007). Concurrent sexual partnerships among men in the United States. American Journal of Public Health, 97(12), 1-8.

Dugatkin, L.A. (1992). Sexual selection and imitation: Females copy the mate choice of others. The American Naturalist, 139(6), 1384-1389.

Dugatkin, L.A. (1996). Copying and mate choice. In C.M. Heyes \& B.G. Galef, B (Eds.), Social learning in animals: The roots of culture (85-105). London: Academic Press.

Dunn, M.J., \& Doria, M.V. (2010). Simulated attraction increases opposite sex attractiveness ratings in females but not males. Journal of Social, Evolutionary and Cultural Psychology, 4(1), 1-17.

Eva, K. W., \& Wood, T. J. (2006). Are all the taken men good? An indirect examination of mate-choice copying in humans. Canadian Medical Association Journal, 175(12), 15731574.

Galef, B. G., Jr. (2008). Social influences on the mate choices of male and female Japanese quail. Comparative Cognition and Behavior Reviews, 3, 1-12.

Greely, A.M., Michael, R.T., \& Smith, T.W. (1990). Americans and their sexual partners. Society, 27(5), 36-42.

Hendrie, C.A., Mannion, H.D., \& Godfrey, G.K. (2009). Evidence to suggest that nightclubs function as human sexual display grounds. Behaviour, 146, 1331-1348.

Little, A.C., Burriss, R.P., Jones, B.C., DeBruine, L.M., \& Caldwell, C.A. (2008). Social influence in human face preference: men and women are influenced more for long-term than short-term attractiveness decisions. Evolution and Human Behavior, 29(2), 140146.

Milonoff, M., Nummi, P., Nummi, O., \& Pienmunne, E. (2007). Male friends, not female company, make a man more attractive. Annales Zoologici Fennici, 44(5), 348-354.

Parker, J., \& Burkley, M. (2010). Who's chasing whom? The impact of gender and relationship status on mate poaching. Journal of Experimental Social Psychology, 45(4), 1016-1019.

Journal of Social, Evolutionary, and Cultural Psychology - ISSN 1933-5377 - Volume 6(1). 2012. 
Penton-Voak, I.S., Pound, N., Little, A.C., \& Perrett, D.I. (2006). Personality judgments from natural and composite facial images: more evidence for a "kernel of truth" in social perception. Social Cognition, 24(5), 607-640.

Place, S.S., Todd, P.M., Penke, L., \& Asendorpf, J.B. (2010). Humans show mate copying after observing real mate choices. Evolution and Human Behavior, 31(5), 320-325.

Platek, S.M., Burch, B.L., \& Gallup Jr., G.G., (2001). The reproductive priming effect. Social Behavior and Personality, 29(4), 245-248.

Pruett-Jones, S. (1992). Independent versus nonindependent mate choice: Do females copy each other? The American Naturalist, 140(6), 1000-1009.

Rosenberg, M. (1965). Society and the adolescent self-image. Princeton, NJ: Princeton University Press.

Rushton, J.P., Brainerd, C.J., \& Pressley, M. (1983). Behavioral development and construct validity: The principle of aggregation. Psychological Bulletin, 94(1), 18-38.

Schlupp, I., \& Ryan, M.J. (1997). Male sailfin mollies copy the mate choice of other males. Behavioral Ecology, 8(1), 104-107.

Schmitt, D.P. (2004). Patterns of universals of mate poaching across 53 nations: The effects of sex, culture and personality on romantically attracting another person's partner. Journal of Personality and Social Psychology, 86(4), 560-584.

Schmitt, D.P., \& Buss, D.M. (2001). Human mate poaching: Tactics and temptations for infiltrating existing mateships. Journal of Personality and Social Psychology, 80(6), 894-917.

Seidman, S.N., \& Rieder, R. O. (1994). A review of sexual behavior in the United States. American Journal of Psychiatry, 151(3), 330-340.

Sigall, H., \& Landy, D. (1973). Radiating beauty: Effects of having a physically attractive partner on person perception. Journal of Personality and Social Psychology, 28(2), 218224.

Singh, D. (1993). Adaptive significance of female physical attractiveness: Role of waist-to-hip ratio. Journal of Personality and Social Psychology, 65(2), 293-307.

Singh, D., \& Young, R.K. (1995). Body weight, waist-to-hip-ratio, breasts, and hips: Role in judgments of female attractiveness and desirability for relationships. Ethology and Sociobiology, 16(6), 483-507.

Silvera, D.H, Martinussen, M., \& Dahl, T.I. (2001). The Tromso Social Intelligence Scale, a self-report measure of social intelligence. Scandinavian Journal of Psychology, 42(4), 313-319.

Smith, T.W. (1992). Discrepancies between men and women in reporting number of sexual partners: A summary from four countries. Social Biology, 39(3-4), 203-211.

Tovée, M.J., \& Cornelissen, P.L. (2001). Female and male perceptions of female physical attractiveness in front-view and profile. British Journal of Psychology, 92(2), 391-402.

Uller, T., \& Johansson, L. C. (2003). Human mate choice and the wedding ring effect: Are married men more attractive? Human Nature, 14(3), 267-276.

Vakirtzis, A. (2011). Mate choice copying and nonindependent mate choice: a critical review. Annales Zoologici Fennici, 48(2), 91-107.

Vakirtzis, A., \& Roberts, S.C. (2009a). Mate choice copying and mate quality bias: different processes, different species. Behavioral Ecology, 20(4), 908-911.

Vakirtzis, A., \& Roberts, S.C. (2009b). Mate quality bias: Sex differences in humans. Annales Zoologici Fennici, 47(2), 149-157.

Vakirtzis, A., \& Roberts, S.C. (2010). Nonindependent mate choice in monogamy. Behavioral Ecology, 21(5), 898-901.

Journal of Social, Evolutionary, and Cultural Psychology - ISSN 1933-5377 - Volume 6(1). 2012. 
Waynforth, D. (2007). Mate choice copying in humans. Human Nature, 18(3), 264-271.

Westneat, D. F., Walters, A., McCarthy, T. M., Hatch, M. I., \& Hein, W. K. (2000). Alternative mechanisms of nonindependent mate choice. Animal Behaviour, 59(3), 467-476.

White, D. J. (2004). Influences of social learning on mate-choice decisions. Learning and Behavior, 32(1), 105-113.

Widemo, M.S. (2006). Male but not female pipefish copy mate choice. Behavioral Ecology, 17(2), 255-259.

Wiederman, M.W. (1997). The truth must be in here somewhere: examining the gender discrepancy in self-reported lifetime number of sex partners. The Journal of Sex Research, 34(4), 375-386.

Witte, K., \& Ueding, K. (2003). Sailfin molly females (Poecilia latipinna) copy the rejection of a male. Behavioral Ecology, 14(3), 389-395.

Yorzinski, J.L., \& Platt, M.L. (2010). Same-sex gaze attraction influences mate-choice copying in humans. PLos ONE, 5(2), e9115 